\title{
The Water Management in Tunisia: A Trend towards Unconventional Resources
}

\author{
Ali BOUCHRIKA ${ }^{1}$, Habib JOUBER $^{2, *}, \&$ Wajdi BARDI $^{3}$ \\ ${ }^{1,3}$ Higher Institute of Management, University of Gabès, Tunisia \\ ${ }^{2}$ LARTIGE, Higher Institute of Management, University of Gabès, Tunisia \\ *Corresponding author E-mail:jouberhabib@yahoo.com
}

Received: Oct. 14, $2014 \quad$ Accepted: March 12, $2015 \quad$ Published: April 1, 2015

doi:10.5296/jmr.v7i3.6450 URL: http://dx.doi.org/10.5296/jmr.v7i3.6450

\begin{abstract}
This article analyses the current situation of water management in Tunisia focusing on constraints to which this management is subject. The empirical results show the absence of a long-term equilibrium between production capacity and consumption patterns. This imbalance is characterized by a deficiency in the quantity of water produced, that is to say that the quantities applied for exceed those produced for future projection. Currently, as the closer one gets to a full phenomenon which is the use of available resources, a trend towards unconventional resources such as treated wastewater (TW) may solve the problem although partially.
\end{abstract}

Keywords: Water, Time series, Treated wastewater 


\section{Introduction}

Water is primarily a natural and ecological property that plays a vital role (Frederico, 1999). However, the water is the origin of life on earth. It is essential for many industries. The screen, this resource has been considered as a single fluid or chemical, so today it is seen as a way of life that must be preserved quantity available. Therefore, the water must be managed as a valuable heritage, so that its use is organized to allow optimal satisfaction of all needs, acting on a demand management. Piont (1999) showed that the application of the analysis is focused on the water needs. Thus, the quantities of water consumed and the prices depend on the evolution of the people and their lifestyle. In this context, such a control program should be based on effective management of services integrating primary efficacy endpoints (Boyer et al., 1999). Studies by Point (1999), Hansen (1998), Agthe and Billing (1996), Hogland (1997) Rewick and Archibald (1998) emphasized aspects allowing the reduction of domestic consumption, including the adoption household water-saving equipment.

It was reported that the first studies on the demand for residential water use occurred in the United States from the sixties with the pioneering works of Howe and Linawearver (1967), Danielson (1978) and Foster and Beatlie (1981). Indeed, the principle of demand management is based primarily on the establishment of a true pricing policy to put pressure on demand. In this guideline and Sovedoff Spiller (1999) present an economic model, supported by a number of empirical studies on water management, as defined by the application of a low pricing. In addition, Margat (1992) stresses that water pricing takes into account the economic, legal and environmental aspects, the aim is to achieve economic efficiency and social equity within the national economy. Previously, Dupuit (1949), hoteling (1938) and Vickrey (1942) showed a marginal cost pricing, which aims to produce optimal amounts. In other words, among the works that are interested in estimating the function of water demand include the work of Howe (1982) which relates consumption and prices through an analysis section. Whintington et al., (1991) have estimated a demand function of water to assess the willingness to pay of the population to benefit from a water supply.

In general, it appears that the price of water is not the only factor in water consumption. The various studies and analysis attempt showed that water demand is relatively price sensitive especially for low consumption blocks of a progressive rate. In this theme, Tunisia residential water demand is relatively price sensitive primarily to large consumers' economically dynamic areas that have benefited from alternative sources of supply. However, it is observed in areas of Greater Tunis and North elasticities of -0.77 and -0.59 (Matoussi and Branzini, 1998). In other words, the price increase of the upper part of the rate can be taken to reduce the growth in demand in an undesirable direction. Indeed, consumers will gradually water SONEDE and seek their own power drop. Therefore, this approach can cause negative effects on resource management. Thus, it appears that the charging instrument is not sufficient to preserve the resource, hence the need to think of techniques appropriate regulation by adjusting the conventional and unconventional resources. Given these many problems, the main objective of this paper will focus on the measurement of the current strategy in the management of water resources in Tunisia in terms of economic, social and environmental performance, as well as the principle of regulation for the sustainability of this vital resource. 
The remainder of this paper is organized as follows: the second section focus on a theoretical analysis in the management of water resources. The third section will focus on an empirical methodology to measure the sustainability criteria of the Tunisian strategy in the management of water resources. The fourth section will describe an extension in the current management of water resources in Tunisia based on an unconventional treated wastewater resource. Finally, the fifth section concludes this study.

\section{Theoretical analysis}

The Blue Plan's (2000) report on "Analysis of strategies and outlook of water in Tunisia" deals with the various characteristics of the water resources in Tunisia, as well as policies and strategies that are water currently implemented. Thus, the general field on which are based the current strategies is characterized by high variability in time of water resources, poor distribution of this resource in the territory for different users and strong heterogeneities in the distribution Space saline quality of water resources.

Meet the growing demand for water for the country's development is the strategy adopted by the leaders of the sector to stabilize this trend for. Indeed, the search for maximum technical mastery of all water resources by mobilizing and regularization of most flows and the establishment of an interconnection network, aims to pool national problems of the evolution of consumption. In addition, strategies for water management seeking optimal use of this resource available, they highlight the importance of a national decision optimal resource allocation between uses and between regions.

In addition, some conceptions of demand management, requires taking into account the increase in intra-sector efficiency. It is then to implement economic, technical and regulatory instruments to reduce losses, and stabilize the unit consumption within each use. Allen (1985) points out that this principle of demand management can only be a short term solution, for this reason, demand management is also interested in increasing inter-sector efficiency. Note that the effectiveness of inter-and intra-sector water resources in Tunisia are still problems of distribution and satisfaction.

\subsection{Water resources}

Tunisia is in a semi-arid zone, characterized by insufficient and erratic rainfall, which causes periods of more frequent droughts. For the period 2002-2012, the total water production by SONEDE increases with an average annual growth rate of $3.6 \%$. This production consists of surface water and groundwater. However, surface water produced by various dams totaled 300.55 million $\mathrm{m} 3$ in 2012, including 3.4 million $\mathrm{m} 3$ were recycled for reuse. This resource type represents $53.8 \%$ of the total product. In addition, groundwater produced in 2012 by the various drilling, sounding, well, amounted to 242.3 million $\mathrm{m} 3$ against 178.7 million $\mathrm{m} 3$ in 2002 , representing an average annual growth rate of $3.3 \%$. Is resource type represents $46.2 \%$ of total production. At the beginning of the creation of SONEDE, surface water fed mainly Greater Tunis and some places of the edge of the country. Since 1993, Northern Waters came to the South to fill the gap needs. In addition, and for the needs by region, in 2012 the volume dispensed accused variations ranging from $2.1 \%$ to $1.2 \%$ in North Greater Tunis. The center of 
the country's water supply has decreased by $0.82 \%$. As well as in the South of the country water supply has decreased by $0.44 \%$.

In addition to the problems mentioned, the temporal variability, that is to say, the availability of the resource between years and spatial variability which is checked by the unequal distribution of resources between different regions of the country, makes management of this resource is tricky. Indeed, like any other country subject to a Mediterranean climate, Tunisia is facing a strong seasonal variability of rainfall and surface water so focused on the winter season. This seasonal variability is coupled with a strong inter-annual variability (severe drought, those of 1989-1992). However, to fight against such variability, it will provide great works for storing high flows rivers in years of high rainfall.

On the other hand, the distribution of rainfall involves major imbalances between North and sometimes very wet desert south. Indeed, the Greater Tunis region and the region of North are generally staffed by surface waters which have the largest share of available resources. In contrast, the South region is generally provided by groundwater resources that are most available resources. Alternatively, the non-coincidence of development zones with such allocation of resources can lead to problems of development of water resources to ensure a certain national equalization.

\subsection{The challenges of the water sector}

In recent years, the potential water resources, including groundwater in Tunisia is limited to $48.2 \mathrm{~km} 3$ of which only $4.11 \mathrm{~km}^{3}$ are mobilized by hydraulic facilities. Surface runoff is more irregular rainfall over a period of 20 years is very random. There is an average of three wet years, six years and eleven average deficit five years are dry. In addition, these resources are very unevenly distributed across the country and $51.7 \%$ of these resources have only a salinity of less than $1.5 \mathrm{~g} \backslash 1$ and $24 \%$ of resources are characterized by poor quality, where the salinity is greater than $3 g \backslash 1$.

However, in Tunisia, the water resource is rare and random, which is an obstacle facing the economic and social development. In addition, and although the control of population growth, the rational management of water resources and the economic choices made by Tunisia are very significant, the growing mismatch between the needs of the population by water and food needs poses many problems. The general principle of the water supply is a centralized decision that may arise in the mostly problems that often result from poor distribution between regions and between users. The short-term consequences of this principle are clear to allocate access to water equitably throughout the country based on the location of users, but in the long term, this principle can focus on other users in terms of quantitative and qualitative satisfaction.

On the other hand, how the pricing of water is one of the tools for rationalizing the consumption of this vital resource. In this context, policy SONEDE is based primarily on a non-linear pricing per consumption and whose objective is to penalize the consumer groups who waste the most water resources. Note that the average selling price of water has experienced an average growth of $2.3 \%$ per year during the period 1971 and 2012. At the sector level price changes experienced multiple disparities. Indeed, on the domestic and industrial 
sector, the price has increased quite progressive and especially for lower consumption bands. However, the tourism sector, the price was uniform and since 1984 this price is equal to the price of the last tranche (151 or more) domestic and industrial use.

\section{Empirical methodology}

In a context of sustainable management of water resources, scarcity can be a barrier that coincides with the political management of this resource. Furthermore, the population growth followed by increasing the number of users further complicates the problem. Thus, the extent to which current policy of water management in Tunisia can stand before these constraints?

Considering the growing demand for water development needs of the country, the optimal strategy for water management seeks to maximize the use, conservation of this resource and the achievement of social justice to achieve an economic balance long term. It is to implement economic, technical and regulatory instruments to reduce losses and stabilize the unit water consumption. Moreover, the empirical study of the evolution of two variables consumption and total production over time allows us to observe non-preferred results to achieve sustainable management. For this reason we consider the annual series of these two variables available on the period from 1971 to 2012. Graphs (1) and (2) show that the two series appear to have a common upward trend throughout the period. Therefore, the two series appear non-stationary and because of their apparent similar trend, it is legitimate to be interested in the study of cointegration between these two variables (Sandrine and Valerie, 2002).

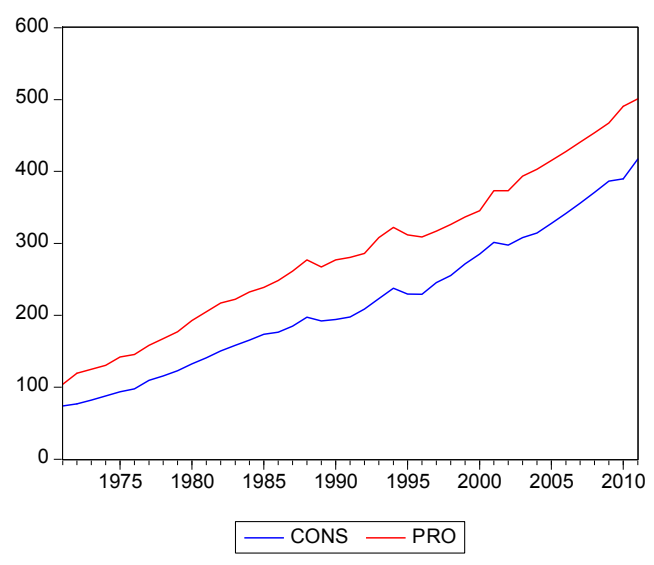

Graph 1. Evolution of total consumption and production

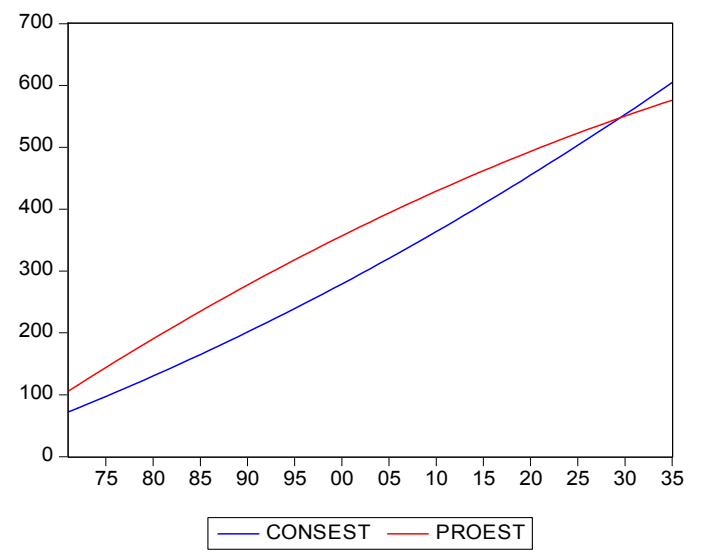

Graph 2. Estimated consumption and production increases

Insofar, as the method of Engle and Granger (1987) is valid only for integrated series of order 1, it should first determine the order of integration of each of our series. To this end, we apply the Dickey Fuller on consumption and output series. The results show first that the series is non-stationary use, the estimated ADF statistics (-0.76) value is greater than the critical value 
$(-2.96)$ at $5 \%$. Similarly, and secondly the results show non-stationary serial production, the estimated ADF statistic (-0.132) value is greater than the critical value (-2.96) the statistical threshold of $5 \%$. Therefore, the null hypothesis of unit root test series in first difference stationary provided two sets of consumption and production, given the estimated values and critical and statistical threshold of $5 \%(-3.43<-2.96,-3.04<-2.96)$.

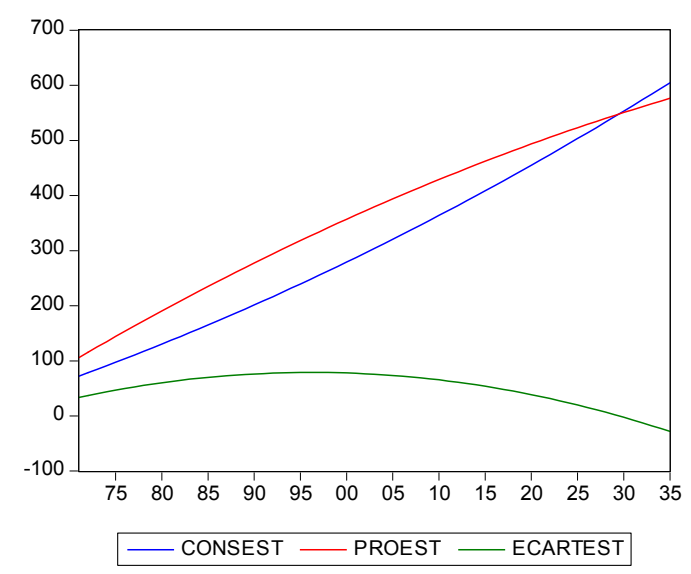

Graph 3. The consumption and production estimated deviation

In addition, the estimation of the statistical relationship between consumption and production, aims to deduce the series of residues. The results of the application of the ADF test on the series of residues that show the statistical relationship non-stationary of the series at the $5 \%$ level. Indeed, the estimated ADF statistics (-2.56) is greater than the critical value (-3.29) (Engle and critic Yoo's (1987) value) and the estimated between consumption and production is a relationship spurious regression. Therefore the series of consumption and production are not co-integrated that is to say, there is not a long-term balance between these two variables, and this poses a problem in the management of water in Tunisia for future projection.

However, this imbalance between the structure of consumption and production capacity, may be due to either a convergence or a divergence between these two variables, that is to say in excess or in the production capacity where a deficit. For this reason, in the remainder of this analysis we will try to demonstrate the origin of this imbalance. It is obvious that if the growth rate of the consumption function follows an incompatible with that of the production function pace, then this may be a barrier to achieving a balance between long-term changes in these two variables. For this reason, and to confirm the origin of the deficit in the evolution of consumption and production water in Tunisia, we will look at a projected study between these two variables to determine the source of this imbalance.

From the graph above and assuming that the linear fit performed on the 39 periods for both variables (consumption - production) remains to verify the future horizon to the extent that implicitly assumes the absence of changes structural change in the structure of consumption 
and production capacity, a cross between the evolution of these two variables could be reached between the period 2029 to 2030 .

For this period, the estimated difference between production and consumption is negative. It equals $-2.594 \mathrm{Mm}^{3}$, resulting in a deficit in the structure of consumption of this vital resource for future projection.

Considering this critical situation, decision makers in the sector must prepare and adopt adequate procedures to overcome the crisis in the future management of water and protect future generations. It was noted that the analysis provided in the current policy of water management in Tunisia show amazing results in the structure of the demand function. Thus, the strategy now reached almost the limit for the scarcity of this vital resource. Therefore, it becomes necessary to create other forms of regulation that are verified by an orientation towards unconventional resources to ensure the sustainability of water which becomes dramatically rare.

\section{Extension in the current management of water resources in Tunisia:}

Considering the scarcity of conventional resources, public authorities must be prepared to devise new strategies able to recover deficits in the limited production capacity.

\subsection{Policy unconventional resources: The treated wastewater}

The situation in which water resources are limited is under the influence of anthropological factors such as overexploitation and population growth in some countries. In addition, water resources are unevenly distributed, leading to dramatic situations of local and regional shortages. In many countries, water scarcity leads to a depletion of conventional resources, resulting in a wastewater reuse mainly for irrigation. Note that agricultural irrigation is the largest consumer of water and offers the greatest potential for implementation of reuse schemes Waste Water. However, the need for non-conventional water resources is the most critical in the area of reuse of treated wastewater factor. The potential for wastewater reclamation and reuse are currently far from being exploited in many parts of the world, in Tunisia, for example the volume of treated wastewater reuse do not exceed $51233 \mathrm{~m}^{3} /$ day.

By 2015, the total volume of conventional resource mobilized in Tunisia is estimated at 460 million $\mathrm{m} 3$ and the overall demand is estimated at 405.5 million $\mathrm{m}^{3}$. This shows that this type of resource is almost its limits in the near future. However, Tunisia is characterized by a situation of water stress. Given these constraints, the use of unconventional resources has become a truth to bridge the gap between the available water resource and conventional estimated demand. Indeed, the Tunisian medium-term strategy is based on the following unconventional resources: reuse of treated wastewater (TW), the desalination of brackish water and artificial recharge. Furthermore, the use of treated wastewater can ensure the realization of several advantages such as economy of conventional and stability thereof, the protection of receiving environments and the preservation of some wetlands water resources.

In this guideline, the reuse of treated wastewater could help to significantly reduce water scarcity in countries located in arid and semi-arid. It should be noted that in these countries 
agriculture is the largest user of water in Tunisia, for example, it affects about $80 \%$ of total resources. Substitution of conventional water resources by TME in irrigation is the most important quantitative potential reuse of wastewater. However, wastewater reuse can present a complex theme. Indeed, it must not only take into account the infrastructure and processing technologies, but also the key parameters such as quality as defined in national legislation. In this issue, the level of quality that meets the needs of society and the environment can be achieved through some processing technology.

In other words, in most southern Mediterranean countries, the capacity of existing treatment plants (TPs) are far from meeting demand, which then requires the construction of new infrastructure. Note that the option of potential reuse of treated depends quantitative water requirements, as well as level of quality requirement. In this perspective, there are two approaches: bottom-up and top-down. Indeed, the approach bottom-up is to determine reuse options provided and techniques required treatment. Moreover, this approach will provide the largest selection of water reuse option to achieve economic profitability. While the top-down approach focuses on the quality of treated wastewater to existing and define reuse options possible.

In the analysis of the physical nature of the water resources in the treated wastewater, it was noted that in most countries, industrial wastewater has a particular problem. Indeed, they are often toxic. Therefore, this problem must be addressed at the industrial site strengthening existing laws pre wastewater. In other words, the major potential source of water collection is presented primarily by municipal wastewater. These are formed in mostly by domestic wastewater. Other sources of water harvesting are those of gray water, but in small quantities. This type of resource is a part of domestic wastewater collected separately (showers, sinks, kitchens, washing, etc.). Storm water drainage and are a poor source of water recovery. For this type of source, method of collection and storage can affect their quality. Reuse of gray water and storm water requires the collection and use of separate distribution systems. Therefore, in many countries, this system is not available and could represent a significant cost factor.

Various studies bearing on the processing technology treated wastewater show diversity in treatment techniques. Therefore, the technological options available are very diverse, and whose effectiveness depends on the quality of the operation, maintenance and quality influential. Currently, reuse options most observed in most of the world is based, firstly, on the application of treated wastewater for irrigation in agriculture and green spaces, and secondly, on the recharge of aquifers. Indeed, in industrial practice, the majority of the volume of treated wastewater generated can be used and generally considered water recycling. Therefore the use of treated wastewater in industrial use can get more profits in any industry in reducing the development of new water supply systems. It was reported that the reuse of treated wastewater is increasingly applied as a supplement or substitute fresh water in industrial consumption. Therefore, the major factors influencing industrial wastewater include availability, reliability of the source generating the water quality requirements. However, membrane technologies are increasingly used; they offer the possibility of producing good quality water. 


\subsection{Economic analysis of the reuse of treated wastewater}

Currently, agriculture is the largest sector in the field of reuse of treated wastewater. However, the fundamental obstacle to sustainable financing schemes for wastewater reuse is verified by the fact that irrigation water in public perimeters is free or is sold below its value. Indeed, free water for farmers is a habit that takes place in many countries. Therefore, this causes extremely high subsidies that complicate the introduction of market prices for fresh water and waste water recovered. In the same guideline, seen on the policy rate and practiced the principle of cost recovery show that income from a water pricing and government subsidies are the only sources of funding costs. In this situation several countries such as Tunisia subsidize the price of water, this is done either directly or from funding from major investments (dams, centralized networks), which make it one of the costs of operation and maintenance is covered by water pricing.

In addition, actual costs must be known before taking an investment decision in draft wastewater reuse to ensure their economic performance. In this perspective the economic approach adopted is known as "dynamic technology costs." For the production of water, these dynamic costs reflect all costs for the life of an investment project. In addition, these dynamic costs are based on calculations of water pricing and the amounts of government subsidies are necessary to ensure the operation and maintenance of long-term investment projects.

For projects treated wastewater reuse, the price of reuse is not systematically higher than that of conventional water prices. Reuse for agricultural, industrial and tourist, pricing water can not cover some of the costs, which require re-compensation by government grants. In addition, irrigation of landscaped areas is a public duty which should be financed from government budgets. In case of return for reuse options that must meet certain quality requirements, the goal will be to reach the entire recovery costs, including capital costs, storage and distribution infrastructure from rates paid by users. In other words, to ensure a certain level of cost recovery, operators in the water sector and sanitation have applied a comprehensive approach to implementation rates to create cross-subsidies between the various sectors. However, this willingness to pay generally depends on several criteria. Mention may be made, inter alia:

- The scarcity of resources: the more conventional water resources are limited more users are willing to pay a high price.

- Costs of resources: more costs are high more users are willing to pay for alternative sources has a similar price.

- The quality of the resource: the higher the quality of the water supplied is good, more users are willing to pay.

- Services of Supply: TME users may be more willing to pay a high price when service improvement.

Following the various analysis mentioned above, the use of treated wastewater is in contrast with many constrains. Indeed, a first constraint may be due to lack of infrastructure, which requires processing of the quantities of the collected wastewater. In addition, economic 
constraints are related to the sustainable financing of investment and operating costs at wastewater treatment plants (TPs), and reuse schemes. This is mainly due to the ineffectiveness of rate applied is far to cover the costs, the lack of government funding, and the limited willingness and ability to pay for the treated wastewater. Let us note also that the application of legislation and compliance standards are quite low and often with limited quality control. For this reason, the sustainable financing of operating costs and maintenance is necessary, they must be guaranteed by an effective pricing or additional government subsidies.

\subsection{Reuse of treated wastewater in the Tunisian context}

Tunisian strategy for reuse of treated wastewater is promising. It is based on two main levers namely the substitution of conventional water by the treated wastewater at the water-consuming activities and the creation of a new application with strategic projects in a long-term planning. The achievement of these two objectives is likely conditioned by strengthening the legal and institutional framework, the quality control and the gradual integration of the reuse of treated wastewater in the management of water resources and the adoption of a policy of adequate. Pricing annual estimates of the capacity of unconventional resources in Tunisia are listed in the following table:

Table 1. Non conventional water ressources estimed by $\mathrm{Mm}^{3} /$ year

\begin{tabular}{|l|l|l|l|l|}
\hline Year & 1996 & 2010 & 2020 & 2030 \\
\hline Quantity & 120 & 210 & 314 & 389 \\
\hline
\end{tabular}

Concerning quality control in Tunisia, the treated wastewaters are subject to NT 106.02 standard approved July 20, 1989 before being released in aquatic environments. This standard defines the quality of the effluent as a function of the receiving environment, and release thresholds of 54 parameters. It should be noted that the comparison of treated wastewater from a dozen sewage treatment plants (TPs) showed that the chemical water quality differs from one station to another. This is mainly due to the quality of the water supply at the site of the treatment plant, the proportion of industrial water compared to domestic sewage and treatment system. In addition we note that salinity TME differs between STEP. This difference can be justified by the mode of treatment by the sealing of the sewerage network and even the quality of the water. In this respect, it is estimated that the salt concentration in domestic wastewater is 200 to $300 \mathrm{mlg} / \mathrm{l}$ while the annual average dry residue in the TW is between 1 and $15 \mathrm{~g} / \mathrm{l}$. Clinical analysis shows that currently the STEP in the North West of the country provide the best quality in terms of salinity varies between 1 and $1.5 \mathrm{~g} / \mathrm{l}$. However, the dry residue varies between 2.8 and $6 \mathrm{~g} / 1$ for the Greater Tunis, $1.6 \mathrm{~g} / 1$ and $2.6 \mathrm{~g} / 1$ for the North East, $1.8 \mathrm{~g} / 1$ and 4.6 $\mathrm{g} / 1$ for the center and the Sahel.

The last lever of the Tunisian strategy wastewater treatment is to gradually promote their reuse in the management of water resources and the application of a specific pricing system. Indeed, the objectives for the 10th development plan are among others to achieve a rate of $60 \%$ reuse of wastewaters for all purposes. In this theme, the reuse of treated wastewater for agricultural purposes requires a single preferential rate of $20 \mathrm{mil} / \mathrm{m}^{3}$, this rate has been adapted from 1997 . Today, the price is a significant variation from one area to the other of $35-116 \mathrm{mil} / \mathrm{m} 3$. In 
addition, a subsidy of about $84 \%$ and is paid on the cost of operation and maintenance schemes concerned. It was noted at the end that the price per cubic meter of treated wastewater has between $20 \%$ and $57 \%$ of the price of conventional water by region for all purposes.

To develop the national strategy to develop treated wastewater conducted by the National Office of Sanitation (ONAS) in 2002, three scenarios were considered. The first scenario is a continuation of existing practices. It is limited to projects identified in the hydro agriculture, golf courses, parks and green space projects. For this reason a reuse rate of $40 \%$ can be achieved by the year 2021. In addition, this scenario is based on the 6,000 ha of irrigation perimeters levels near sewage treatment plants ONAS , 959 acres of parks, six new golf courses and 781 ha for highways. The second scenario is a diversified scenario that takes into account reuse in industry and watering roads. This scenario considers a reuse rate of $62 \%$ by 2021. It sits on the creation of green spaces in major cities (280ha) and hotel gardens (30\% of the area of tourist areas). In the industrial sector believes reuse potential $29 \mathrm{Mm}^{3}$ and inter seasonal storage for recharge of coastal aquifers. The third scenario and a scenario based on agricultural development reuse of treated wastewater in agriculture and groundwater recharge. For this scenario, a reuse rate of $57 \%$ is expected by the year 2021 .

It is noted that in the evolution of the use of treated wastewater must ensure that environmental supports should take advantage of these resources wastewater. This concern for the environment can be defended institutionally through an administration or environmental lobby. In other words and to minimize pressure on conventional resources, experiences show that it is necessary to formulate next to the goal of greater efficiency per unit volume of water, a second objective which should limit the total amount or share of conventional water for agricultural and industrial use. However, the quantities produced unconventional water must be integrated in the ability of municipal water production is for this reason that the use of treated wastewater becomes more interesting especially for the three sectors namely industry, tourism and agriculture. In addition, acceptance of food products that have been irrigated with wastewater from consumers can minimize the share of conventional resources in irrigated areas. Note that the empirical research shows that the purchase of these products is increasing acceptance with the geographical distance between the consumer and the producer.

About the above mentioned analysis, we can see that the use of treated wastewater has more advantages than disadvantages for most players. Indeed, a multiple use of water, one can find a use rate of $50 \%$ TME saved up $7.5 \%$ of the total amount of conventional water available. However, to achieve the national target for use of treated wastewater, it is necessary to create additional simulation should permit use of the treated wastewater profitably for all farms. In Tunisia, the investment costs and costs of operations for further processing amounted to about $10 \%$ of the costs of construction and operation of a conventional wastewater treatment plant in two treatments. In this situation, the creation of a regulatory system must necessarily pass through the construction of a tariff system in TME resource for the three sectors, namely industry, tourism and agriculture, in order to enhance the $\mathrm{m}^{3}$ this resource. Therefore, investment in these types of resources TME aims to increase the production capacity of the well water and cover the deficit expected in conventional resources for future projection. Indeed, the integration of non -conventional resources with conventional resources for 
collecting total amount of well water, among others allows us to carry forward the following relationship:

$$
\mathrm{QT}=\mathrm{CR}+\mathrm{RNC}
$$

Where;

QT: total quantity,

$\mathrm{RC}$ : conventional resources,

RNC: unconventional resources.

As, $\mathrm{RNC}=\alpha \mathrm{RC}$, and $0<\alpha<1$;

Hence, $\mathrm{QT}=(1+\alpha) \mathrm{RC}$

Thus, QT is a monotone function which means that $\alpha$ increases as $\alpha$ increases QT. Where $\alpha$ is an indicator of sustainability. The calculation of this estimate is included in the following table coefficient $\alpha$ given the total available quantities of conventional and unconventional resources estimated for the four periods.

Table 2. Durability'S indexes

\begin{tabular}{|l|l|}
\hline Year & $\boldsymbol{\alpha}$ Estimated coefficient \\
\hline 1996 & 0,03 \\
\hline 2010 & 0,04 \\
\hline 2020 & 0,06 \\
\hline 2030 & 0,07 \\
\hline
\end{tabular}

\section{Conclusion}

Analyses on the current policy of water management in Tunisia show serious problems in the structure of the function of aggregate demand. Indeed, it may be mentioned that the expected decrease in the available capacity of conventional resources forces us to think of additional resources to overcome the future crisis. The reuse of treated wastewater may be a promising technique. Therefore, this resource treated wastewater shall be considered as a solution to achieve a sustainable management of water resources. Since Tunisia is facing water stress in the coming years, the resource TME can minimize the pressure on conventional resources. Hence, this resource TME can recover deficits in the production of conventional resources even partially. On the other hand and to solve the problem related to consumer perception, an awareness program well built and experimental studies towards the users can avoid the constraint of no confidence in the use of treated wastewater by users.

\section{References:}

Agth, D., Billings, R., (1996). Water price effect on residential apartment law-flow. Fixtures Journal of Water Resources Planning and Management, 20-23. http://dx.doi.org/10.1061/(ASCE)0733-9496(1996)122:1(20) 
Allen, V., Bower, T., (1985). The relation of water quality to water use. Management Water Quality Economics Technology Institutions, $380 \mathrm{p}$.

Bahri, A., (2002). Water reclamation and reuse in Tunisia. National Institute for Research on Agricultural Engineering Water and Forestry, Tunis.

Bouchrika, A., Thabet, K., Issaoui, F., (2012). Le management de l'eau potable dans le long terme; vers une gestion plus efficace: application au cas Tunisien. Global Journal of Management and Business Research, 12(3), 103-110.

Boyer, M., Michel, P., \& Pierre, T. (1999). La gestion déléguée de l'eau ; les enjeux. Montréal CIRA N ${ }^{\circ} 52$.

Danielson, L., (1978). An analysis of residential demand for water using. Water Resources Research, 15(4), 763-767. http://dx.doi.org/10.1029/WR015i004p00763

Dupuit, J., (1949). De l'influence des poges sur l'utilité des voies de communication. Annales des ponts et chaussées, $2^{\text {ème }}$ series, 170-248.

Engle, R., F., Granger, C., \& W., J. (1987). Cointegration and error correction representation estimation and testing. Economica. http://dx.doi.org/10.2307/1913236

Engle, R., F., Yoo, S. (1987). Forescesting and testing in cointegrated systems. Journal of Econometrics, 35, 143-159. http://dx.doi.org/10.1016/0304-4076(87)90085-6

Foster, J., H., \& Beattie, B. (1981). On the specification of prices in studies of consumer demand under blook prices scheduling. Land Economics, 57, 624-629. http://dx.doi.org/10.2307/3145676

Frederico, M., (1999). Un monde nouveau. Paris Editions Odile Jacob. 50 pp.

Hamdane, A., (2002). Valeur économique de l'eau agricole; cas de la Tunisie. Forum de la gestion de la demande en eau, Rabat.

Hansen, L., (1996). Water and energy price impacts on residential water demand in Copen Hagen. Land Economics, 72(1), 66-79. http://dx.doi.org/10.2307/3147158

Hoglund, L., (1997). Estimation of house-hold demand for water in Sweden and is implications for a potential tax on water use. University of Goteborg.

Hotelling, H., (1938). The general welfare in relation to problems of taxation and of rail way and utility rates. Econometrica, 6(3), 242-269. http://dx.doi.org/10.2307/1907054

Howe, C., W. (1982). Impact of price residential water demand; new insights. Water Resources Research, 18, 713-716. http://dx.doi.org/10.1029/WR018i004p00713

Howe, C., W., \& Linaweaver, P., F. (1967). The impact of price on residential water demand and is relation to system design and price structure. Water Resources Research, 3(1), 13-32. http://dx.doi.org/10.1029/WR003i001p00013

Margat, J. (1992). Introduction à l'économie générale de l'eau. Economica. 
Matoussi, M., S., \& Branzini, A. (1998). Environmental and water resource. Academy International of the Environment. Geneva Switzerland Working paper.

Ministère de l'agriculture. (2002). Stratégie de l'utilisation des eaux usées traitées.

Neubert, S. (2002). Vastewater reuse in agriculture. A challenge for administration coordination and implementation. Reforming institutions for sustainable water management, IAD Bonn.

OMS (Organisation Mondiale de la Santé). (1989). Guide lines for the safe use of water and wastewater excreta in agriculture and aquaculture measures for public health protection.

Plan Bleu. (2000). Analyse des stratégies et perspective de l'eau en Tunisie.

Point, P. (1993). Partage de la ressource en eau et demande d'alimentation en eau potable. Revue Economique, 4, 849-862. http://dx.doi.org/10.3406/reco.1993.409483

Rewich, M., \& Arechibald, S. (1998). Demand side management policies residential water use who bears the conservation burden. Land Economics, 74(3), 343-359. http://dx.doi.org/10.2307/3147117

Sandrine, L., \& Valerie, M. (2002). Econométrie des séries temporelles macroéconomiques et financières. Economica.

Schuttrumpf, R., \& Mauderli, A. (2002). Stations d'épuration de Karouan, Aousja et Sousse. Réutilisation des eaux usées traitées en agriculture. Rapport de l'expertise. Ministère de l'environnement et de l'aménagement de territoire. Office National de l'Assainissement (ONAS), Tunis.

SONEDE. (2012). Rapport statistique.

Spiller, T., \& Savedoff, D. (1999). Spilled water institutional commitment in the provision of water services. Washington Inter-American Development Bank.

Vickrey, W. (1948). Some objections to marginal cost pricing. Journal of Political Economy, 56, 218-238. http://dx.doi.org/10.1086/256674

Whitington, D., Louria, D., \& Mu, X. (1991). A study of water vending and willingness to pay for water in onitsha. Nigeria Word Development, 19, 179-198. http://dx.doi.org/10.1016/0305-750X(91)90254-F

Zekri, A. (1995). Les externalités négatives de l'utilisation des eaux usées traitées en agriculture. Séminaire sur les aspects économiques de la gestion de l'eau dans le bassin méditerranéen, Marrakech. 